\title{
Effect of Wine Closures on the Aroma Properties of Chardonnay Wines after Four Years of Storage
}

\author{
N. Liu ${ }^{1}$, Y.-Y. Song ${ }^{1}$, G.-F. Dang ${ }^{1}$, D.-Q. Ye ${ }^{1}$, X. Gong ${ }^{1}$, Y.-L. Liu ${ }^{1,2^{*}}$ \\ (1) College of Oenology, Northwest A\&F University, Yangling, Shaanxi 712100, China \\ (2) Shaanxi Engineering Research Centre for Viti-Viniculture, 22 Xinong Road, Yangling, Shaanxi 712100, China
}

Submitted for publication: January 2015

Accepted for publication: March 2015

Key words: Closures, sensory properties, Chardonnay wine, aroma profiles

\begin{abstract}
The effects of wine closures on the sensory properties and aroma profiles of fresh Chardonnay wines were evaluated after four years of bottle storage. Natural cork closure, technical cork closure, Nomacorc light, Nomacorc classic and Nomacorc premium were investigated. Among these wines sealing with different closures, the physicochemical parameters of the wine samples showed no significant differences, except that of the free and total sulphur dioxide. Nomacorc light with the highest OTR (oxygen transition rate) had the least residual free sulphur dioxide. Most of volatiles were generally stable, and seven compounds (acetoin, 1-butanol, 2-phenylethanol, 1-pentanol, $(Z)$-3-hexen-1-ol, 2-nonanol and ethyl decanoate) were significantly affected by the wine closures. The sensory analysis revealed that cork closures preserved more fruity/flowery characters of the fresh wines after four years' storage, as well as cork-tainted off-flavour. Two synthetic closures (Nomacorc light, Nomacorc classic) imparted some grilled attributes to the wines. Nomacorc premium highly reserved the fruity/flowery flavour without cork contamination or oxidised toasted characters.
\end{abstract}

\section{INTRODUCTION}

Before wine consumption, the majority of wine is subjected to bottling, and bottle storage is the main aspect that most wines have in common. While some wines are stored for a short time, many premium wines undergo a long time of bottle storage for maturation - for several years or decades. During this ageing period in the bottles, the wine changes and maturates gradually. The maturation makes wine reach a state in which its sensory quality is expressed at its maximum, after which the quality of the wine starts declining. This evolution is related to the composition of the wine in bottle storage and determined by many factors, one of which is the type of wine closure.

Its impermeability to liquids/gases and high compressibility and flexibility make cork an ideal closure material for sealing wine bottles. However, corks experience some inevitable problems during bottle ageing, such as TCA (trichloroanisol) contamination, wine leakage and undesirable oxidation (Karbowiak et al., 2010). Recently, synthetic closures have been reported to be able to eliminate these disadvantages of corks in ageing in the wine bottle (Silvestre et al., 2008). As the synthetic closures are able to prevent wine leakage and contamination, they have been commercially available and widely used for sealing wine bottles (Silva et al., 2005). The use of synthetic closures has increased gradually in the American market, from $14.5 \%$ in 1996 to $33 \%$ in 2008 (Cathy, 2007; 2008).

There have been several reports of studies on the effect of closures on wine development after bottling (Godden et al., 2001; Escudero et al., 2002; Field et al., 2003; Brajkovich et al., 2005; Skouroumounis et al., 2005; Caille et al., 2010; Silva et al., 2011; Wirth et al., 2012), with the most extensive to date being that of Godden et al. (2001). These studies compared and monitored the compositional and sensory data of 14 different closure types and demonstrated that the screw cap was the best performer, with less wine oxidation, followed by cork closures. Those wines sealed with synthetic closures, however, developed in a different way and acquired a high level of oxidised/aldehyde aroma. In contrast to Godden et al. (2001), Mas et al. (2002) concluded that the most suitable closures for wine evolution were natural corks, although wine sealed under natural corks showed some reduced characters (Skouroumounis et al., 2005). As part of ongoing research on wine closures, a number of studies on wine oxidation post-bottling have been performed. Most of the studies focused on the effects of wine closures on the sensory evaluation of the wine after months of bottle storage. The wines studied were mainly red wines

\footnotetext{
*Corresponding author: E-mail address: yanlinliu@nwsuaf.edu.cn [Tel.: +86-29-87092931; Fax: +86-29-8709293]

N. Liu and Y.-Y. Song contributed equally to this work

Acknowledgements: This study was funded by a grant from China Agriculture Research System [CARS-30-jg-3]. We are thankful for the technical assistance of the Centre for Viticulture and Oenology, College of Food Science \& Nutritional Engineering, China Agricultural University. We also are grateful to Dr Xu, for his critical reading of the manuscript
} 
of Cabernet Sauvignon or Grenache, and white wines of Riesling, Semillon or wooded Chardonnay. In this study on the impact of closures, the focus was on the compositional and sensory differences among wines sealed with different closures after four years of bottle storage. This study was undertaken on fresh Chardonnay wine, the wine style of economic importance to the Chinese wine industry.

\section{MATERIALS AND METHODS}

\section{Wine closures}

Five types of commercial closures were tested in this trial. Three synthetic closures, namely Nomacorc light, Nomacorc classic and Nomacorc premium, were supplied by Nomacorc LLC, China. Nomacorc closures are made from polyethylene by a co-extrusion process. The co-extrusion process consists of two stages: first, raw materials are mixed, melted and extruded to create a long, foamed cylinder, forming the closure's core; then a second extrusion process applies a flexible outer skin, which is thermally bonded to the inner cylinder. Two types of conventional corks also were used, namely natural cork closure (Colombin GM, Italy), and technical cork closure (Bida LLC, Beijing, China).

\section{Wine preparation}

Vitis vinifera L. $c v$. Chardonnay grapes were hand-harvested at $20^{\circ}$ Brix from the vineyards in the Manasi region in the 2006 vintage. The grape must had the following composition: $205.6 \pm 0.5 \mathrm{~g} / \mathrm{L}$ of sugars, $5.12 \pm 0.03 \mathrm{~g} / \mathrm{L}$ of total acidity as tartaric acid, and a $\mathrm{pH}$ of $3.76 \pm 0.01$. The Manasi region is located in Xinjiang province in the northwest of China, lies west of Urumchi, surrounded by mountains, and belongs to the typical arid or semiarid continental monsoon climate in a warm temperate zone. The white wine was made by the Guo'an wine company LLC (Xinjiang, China) according to the traditional winemaking protocol. Wines were fermented in stainless steel tanks and the fermentation temperature ranged from 14 to $17^{\circ} \mathrm{C}$. After fermentation, $\mathrm{SO}_{2}$ was added to $50 \mathrm{mg} / \mathrm{L}$.

\section{Measurement of physical properties of closures}

The dimensions, material density and elasticity of the closures were measured. The dimension was expressed as diameter $\mathrm{x}$ length $(\mathrm{mm} \times \mathrm{mm})$. The density was calculated by dividing the weight by the volume of the closure. The elasticity was expressed as the percentage of a ratio of the final diameter obtained after the closure was compressed to $1.55 \mathrm{~cm}$ for $3 \mathrm{~min}$ to its original diameter. Thirty samples were randomly selected to measure each of the property parameters.

\section{Bottles and capping progress}

The wine was put into $750 \mathrm{~mL}$ glass bottles (Bo'ao LLC, Shanghai, China) and capped using equipment from the Bertolaso Company (Italy). The filler was a type of vacuum filling system. All bottles were colourless and manufactured to the following bore specification: a diameter of $18.40 \pm$ $0.1339 \mathrm{~mm}$ at a depth of $3 \mathrm{~mm}$ from the bore entrance; a bore diameter to a depth of $45 \mathrm{~mm}$ from the bore entrance not exceeding $20.10 \pm 0.1231 \mathrm{~mm}$ at any point; a bore diameter at a depth of $45 \mathrm{~mm}$ from the bore entrance being not less than the actual bore diameter at a depth of $10 \mathrm{~mm}$ from the bore entrance at any point. Prior to bottling and capping, bottles were cleaned with sulphurous acid $\left(\mathrm{SO}_{2} 600 \sim 800\right.$ $\mathrm{mg} / \mathrm{L}$ ) and dried by nitrogen (purity $99.99 \%$ ). The fill height, wine temperature, closure insertion depth and headspace pressure of the equipment were also checked pre-run. Fill heights were measured to $61 \mathrm{~mm}$, insertion depths were $0 \pm 1 \mathrm{~mm}$ and the headspace pressure under the closures ranged from $-10 \mathrm{kPa}$ to $0 \mathrm{kPa}$. Thereafter, all the bottles were stored horizontally in ambient air. The changes in the storage conditions for one year (temperature and related humility) are shown in Fig. 1.

\section{General analysis}

Before bottling and four years after bottling, three bottles of wine were chosen randomly to determine physicochemical parameters, such as alcohol content, residual sugars and $\mathrm{pH}$, following the official Chinese methods (GB150382006, 2006). The alcohol content was quantified by GC$7890 \mathrm{~F}$ (Techcomp, China) equipped with a glass-packed column ( $2 \mathrm{~m} \times 2 \mathrm{~mm}$ id; packing with Chromosorb-103 60 80 meshes). Residual sugar (glucose and fructose) was quantified by HPLC-RID10A (Shimadzu Corporation, Japan). The analyses were performed at $2 \mathrm{~mL} / \mathrm{min}$ at ambient temperature with a $150 \mathrm{~mm} \times 5.0 \mathrm{~mm}$ i.d. Shim-pack CLC$\mathrm{NH}_{2}$ (Shimadzu Corporation, Japan) using acetonitrile/ water (7:3) as mobile phase. Free and total sulphur dioxide were evaluated with iodometry; while titratable acidity was
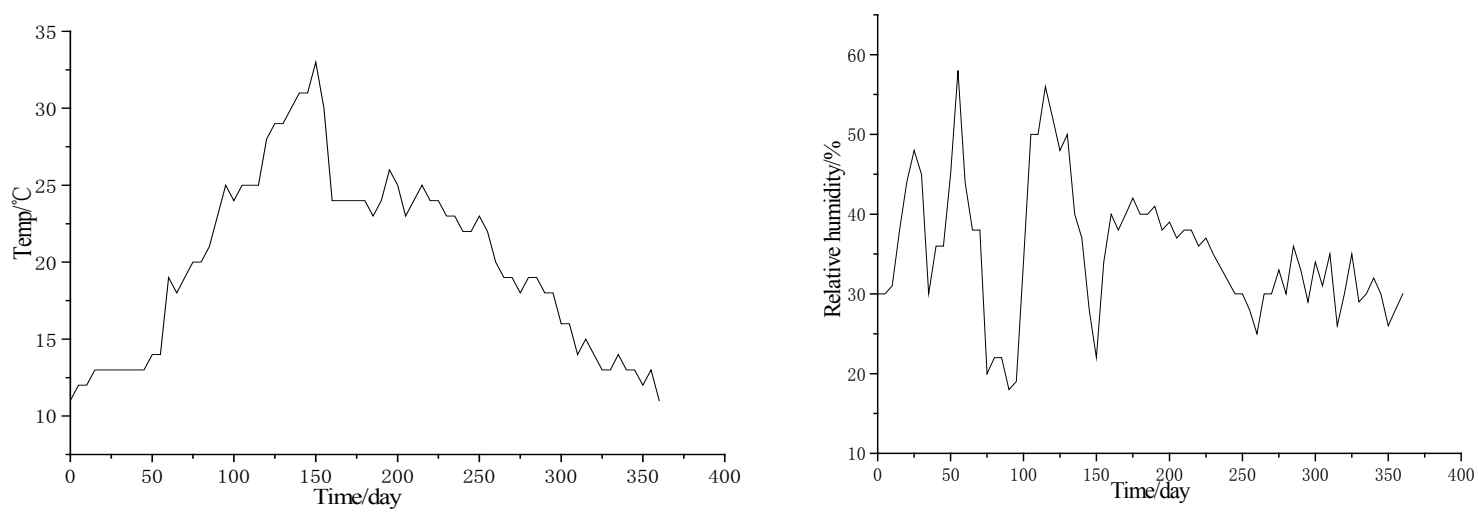

FIGURE 1

Changes in temperature and relative humidity of the storage environment. 
titrated against the standard alkaline solution $\mathrm{NaOH} 0.1$ $\mathrm{mol} / \mathrm{L}$ and volatile acidity after separation from the wine by steam distillation (OIV, 2009).

\section{Analysis of the volatile compounds}

The aroma compounds of each wine were extracted after four years' bottle storage with different closures using a headspace solid phase micro-extraction method (HS-SPME), as described by Zhang et al. (2007). The extracted volatiles were analysed by GC-MS, which consisted of an Agilent $6890 \mathrm{GC}$ and $5975 \mathrm{MS}$ detector and a HP-Innowax capillary column (60 m $\times 0.25 \mathrm{~mm}$ i.d.; $0.25 \mu \mathrm{m}$ film thickness; J\&W Scientific, Folsom, CA, USA).

The standard model solution with $12 \%(\mathrm{v} / \mathrm{v})$ ethanol was prepared in distilled water containing $5.5 \mathrm{~g} / \mathrm{L}$ of tartaric acid, and its $\mathrm{pH}$ was adjusted to 3.7 with $1 \mathrm{~mol} / \mathrm{L}$ $\mathrm{NaOH}$. The volatile standards were dissolved in synthetic matrixes at concentrations typically found in wine. The 32 pure reference compounds were purchased from Aldrich (Milwaukee WI, USA), Supelco (Bellefonte PA) and Fluka (Buchs, Switzerland). They comprised ethyl acetate, isobutyl acetate, isoamyl acetate, hexyl acetate, phenethyl acetate, ethyl lactate, ethyl hexanoate, ethyl octanoate, ethyl decanoate, diethyl succinate, methyl octanoate, 1-butanol, isobutyl alcohol, 1-hexanol, 2-phenylethanol, 1-pentanol, 4-methyl-2-pentanol as the internal standard, $(E)$-3-hexen1-ol, (Z)-3-hexen-1-ol, 1-heptanol, 2-nonanol, benzyl alcohol, 1-octanol, hexanal, furfural, benzaldehyde, acetoin, 4-ethylguaiacol, isobutyric acid, isovaleric acid, octanoic acid and decanoic acid.

Volatiles were identified by the standard retention time and the comparison of the mass spectra to the standards mass spectra, as well as the volatile mass spectra listed in the NIST05a.L library. The quantification of the identified volatiles was carried out using the five-point calibration curves of the respective standards and calculated with the following formula:

the concentration of a volatile $=$ (the volatile's area/4methyl-2-pentanol's area) $\times$ emendation factor to 4-methyl2-pentanol $\times 4$-methyl-2-pentanol's concentration.

\section{Sensory evaluation}

The sensory analysis was performed using the method described by Tao and Zhang (2010). The tasting panel consisted of 30 students (14 males, 16 females, 22 to 24 years old) who had been trained using the "Le Nez du Vin" aroma kit (54 aromas, Yixiangle, Hong Kong). The training was carried out three times a week for 60 to $90 \mathrm{~min}$. An aroma identification test was held every weekend. The completely randomised block design was used for conducting the wine sensory analysis. Wine samples were pre-prepared at $16^{\circ} \mathrm{C}$. Each taster smelled the wines for 5 to $8 \mathrm{~s}$ while still, and then smelled the wines for 5 to $10 \mathrm{~s}$ while swirling the glass. The average time interval between each sample was 1 to $2 \mathrm{~min}$. The aroma profile of each wine was described with five or six terms of "Le Nez du Vin". The intensity of each term was scored on a five-point scale. The data processed were a mixture of intensity and frequency of detection ("modified frequency", MF), which was calculated with the formula proposed by Dravnieks (1985): $M F \%=\sqrt{F(\%) / I(\%)}$, where $\mathrm{F} \%$ is the detection frequency of an aromatic attribute and expressed as a percentage; and I \% is the average intensity expressed as a percentage of the maximum intensity.

\section{Statistical analysis}

For each parameter, the mean and standard deviations (SD) were calculated, followed by ANOVA with post-hoc mean comparison by Duncan's significant difference test for unequal sample size at the 5\% level, using SPSS software version 17.0 for Windows (SPSS Inc., Chicago IL, USA). A two-tailed t-test was used to distinguish the $M F \%$ of aroma characteristics between cork and synthetic closures.

\section{RESULTS AND DISCUSSION}

\section{Variation in physical properties of the closures}

All of the corks and synthetic closures had a flexible structure and resisted damage in the compression for elasticity test. With this in mind, the test conditions and parameters measured for resilience, density and size were implemented to gather comparative information on the mechanical properties of different closures. Table 1 shows that the synthetic closures had greater elasticity than the cork closures. Among these synthetic closures, Nomacorc premium's elasticity was biggest of all and significantly different from the other closures. The statistical analysis of the density parameters showed significant differences among these closures. The density of the synthetic closure, Nomacorc premium, was $451.48 \mathrm{~kg} / \mathrm{m}^{3}$ and the highest of the five closures, while the natural cork closure was the lowest $\left(163.23 \mathrm{~kg} / \mathrm{m}^{3}\right)$. The size (length $\mathrm{x}$ diameter) of the natural corks was similar and slightly bigger than the synthetic closures in length and

TABLE 1

Mechanical properties of closures $(n=30)$.

\begin{tabular}{lllll}
\hline Closures & Resilience $/ \%$ & $\begin{array}{l}\text { Size } / \mathrm{mm}^{2} \\
\text { length } \times \text { diameter }\end{array}$ & $\begin{array}{l}\text { Density } \\
\left(\mathrm{g} / \mathrm{cm}^{3}\right)\end{array}$ & \begin{tabular}{l} 
OTR* $(\mu \mathrm{g} / \mathrm{d} / \mathrm{bottle})$ \\
\hline Natural
\end{tabular} \\
Technical & $98.09 \pm 0.00 \mathrm{a}$ & $43.7 \times 24.3$ & $163.23 \pm 29.82 \mathrm{~d}$ & $0.1 \sim 2.3$ \\
Light & $98.35 \pm 0.01 \mathrm{a}$ & $44.4 \times 23.6$ & $283.46 \pm 16.03 \mathrm{c}$ & $1.7 \sim 6.1$ \\
Classic & $98.53 \pm 0.01 \mathrm{~b}$ & $36.9 \times 22.2$ & $320.52 \pm 2.09 \mathrm{~b}$ & 11.9 \\
Premium & $98.38 \pm 0.01 \mathrm{a}$ & $37.8 \times 22.3$ & $286.91 \pm 2.93 \mathrm{c}$ & 7.4 \\
\hline
\end{tabular}

$\mathrm{a}, \mathrm{b}, \mathrm{c}$ - Same letter in the same column indicates absence of significant differences $(\mathrm{p}<0.05)$

*OTR are from the references of Lopes et al. (2005), Lopes et al. (2006) and the web of Nomacorc (http://www.nomacorc.com/) 
diameter. This is in agreement with the results reported in the studies of Chatonnet et al. (2000) and Godden et al. (2001). The OTRs (oxygen transmission rates) of the closures are expressed as the content of transmission oxygen in each bottle per day and shown in Table 1 . The natural cork closure had the lowest OTR, at $0.1 \sim 2.3 \mu \mathrm{g} / \mathrm{d} /$ bottle, and Nomacorc light had the highest, at $11.9 \mu \mathrm{g} / \mathrm{d} /$ bottle.

\section{Physicochemical parameters of the wines aged in bottles with different closures}

Table 2 shows the main physicochemical parameters of the wines aged in the bottles capped with the five closures. Except for $\mathrm{SO}_{2}$, no significant differences were observed in these parameters among these wines. The volatile acid remained relative stable after four years' storage, varying from 0.53 to $0.58 \mathrm{~g} / \mathrm{L}$, independently of the effect of different closures. Likewise, the $\mathrm{pH}$ value was not significantly influenced by the closures, which is in agreement with Lopes et al. (2009), whose results were similar in that the $\mathrm{pH}$ and volatile acidity in their study change very little in Sauvignon blanc wine after two years' storage. As one of antioxidants in wine, $\mathrm{SO}_{2}$ was greatly affected by the wine closures, with significant differences.

$\mathrm{SO}_{2}$, generated by the metabolism of yeasts, can further be added as an antioxidant and antimicrobial agent (Ugliano 2013). Free $\mathrm{SO}_{2}$ serves as an antioxidant, protecting wine from oxidation, and also can be an indicator of oxygen exposure and oxidative status in wine (Godden et al., 2001). The results demonstrated that both free and total $\mathrm{SO}_{2}$ decreased significantly after the four years, storage, and the decreasing trend agreed with the OTR of each type of closure used to seal the bottles (He et al., 2013). Moreover, differences between conventional cork and synthetic closures were evident. The highest free $\mathrm{SO}_{2}$ was present in the wine with the natural cork closure, followed by the technical cork and Nomacorc premium. Free $\mathrm{SO}_{2}$ with Nomacorc light in the Chardonnay wines was lower than $10 \mathrm{mg} / \mathrm{L}$, which is considered the limit of the protection of white wine (Tominaga et al., 1998).

\section{Analysis of volatile compounds}

Thirty-one volatile compounds were detected by the SPMEGC-MS and are listed in Table 3. Based on their chemical structures, these 31 compounds were classified into 11 alcohols, 11 esters, four fatty acids and five others, including phenol, aldehyde and ketone. Judging from the results in Table 3, wines sealed with different types of closures for four years differed significantly in their content of seven volatile chemicals (acetoin, 1-butanol, 2-phenylethanol, 1-pentanol, (Z)-3-hexen-1-ol, 2-nonanol and ethyl decanoate). Lee et al. (2011) performed a similar study and found that eight volatile chemicals (isoamyl acetate, ethyl decanoate, nonanoic acid, n-decanoic acid, undecanoic acid, 2-furancarboxylic acid, dodecanoic acid and phenylacetaldehyde) contributed to the separation of wine closures and were associated with the degree of oxidation of Cabernet Sauvignon wines.

Aldehydes are very often related to the changes in wine aroma properties linked to oxidation (Azzara \& Campbell 1992). In this study, three aldehydes were detected, and two of them (furfural and benzaldehyde) could satisfactorily predict the cooked-vegetable odour nuance, which is one of the oxidised aroma characters (Escudero et al., 2002; Lee et al., 2011). As shown in Table 3, it was found that the differences in aldehydes among closures did not vary significantly. The wines sealing under natural cork with the lowest OTR had the lowest concentrations of hexanal $(13791.28 \mu \mathrm{g} / \mathrm{L})$, furfural $(552.92 \mu \mathrm{g} / \mathrm{L})$ and benzaldehyde (1145.6 $\mu \mathrm{g} / \mathrm{L})$.

Eleven higher alcohols were identified in this study (Table 3). Among these compounds, 1-butanol, isobutyl alcohol and 2-phenylethanol were more abundant than others in the wines. Using Duncan's test, five alcohols, viz. 1-butanol, 2-phenylethanol, 1-pentanol, (Z)-3-hexen-1-ol and 2-nonanol, were found to differ significantly among these closures. The wine sealed with the Nomacorc premium closure contained the highest quantities of 1-butanol as well as 2-nonanol; the wine sealed with the Nomacorc classic closure contained the highest concentration of $(Z)$-3-hexen1-ol. 2-Phenylethanol contributes a rose fragrance to wine and its peak level was also found in the wine sealed with the Nomacorc classic closure, at $5120.08 \mu \mathrm{g} / \mathrm{L}$.

In addition to alcohols, esters were the other major class of volatiles detected in this study due to their high concentrations and important contribution to flavour. According to their chemical structure, the esters can be divided into three groups: acetate esters, ethyl esters and other esters (Park et al., 2009). Among these esters, only ethyl decanoate was found to be significantly different among the wine closures tested. It is a typical ethyl ester with a long chain fatty acid, contributing to a pleasant or fruity note, and is produced during yeast fermentation by the reactions of ethanol and acyl-coenzyme A derivatives (Câmara et al., 2006). It has been reported that ethyl decanoate decreases

TABLE 2

Physicochemical parameters of experimental wine after bottling.

\begin{tabular}{lllllllll}
\hline $\begin{array}{l}\text { Wine } \\
\text { samples }\end{array}$ & Alcohol $(\mathrm{v} / \mathrm{v}, \%)$ & $\begin{array}{l}\text { Titratable } \\
\text { acidity }(\mathrm{g} / \mathrm{L})\end{array}$ & $\begin{array}{l}\text { Total sugar } \\
(\mathrm{g} / \mathrm{L})\end{array}$ & $\begin{array}{l}\text { Dry extract } \\
(\mathrm{g} / \mathrm{L})\end{array}$ & $\mathrm{pH}$ & $\begin{array}{l}\text { Volatile } \\
\text { acidity* }(\mathrm{g} / \mathrm{L})\end{array}$ & $\begin{array}{l}\mathrm{Free}^{\mathrm{SO}_{2}} \\
(\mathrm{mg} / \mathrm{L})\end{array}$ & $\begin{array}{l}\mathrm{T}^{2} \\
(\mathrm{mg} / \mathrm{L})\end{array}$ \\
\hline Initial & $11.7 \pm 0.1 \mathrm{a}$ & $5.5 \pm 0.2 \mathrm{a}$ & $1.4 \pm 0.2 \mathrm{a}$ & $20.1 \pm 0.3 \mathrm{a}$ & 3.69 & $0.54 \pm 0.02 \mathrm{a}$ & $39.2 \pm 2.3 \mathrm{a}$ & $154.1 \pm 3.4 \mathrm{a}$ \\
Natural & $11.7 \pm 0 \mathrm{a}$ & $5.5 \pm 0.1 \mathrm{a}$ & $1.5 \pm 0.2 \mathrm{a}$ & $20.1 \pm 0.1 \mathrm{a}$ & 3.68 & $0.56 \pm 0.03 \mathrm{a}$ & $22.4 \pm 2.8 \mathrm{~b}$ & $127.0 \pm 4.9 \mathrm{~b}$ \\
Technical & $11.7 \pm 0.1 \mathrm{a}$ & $5.5 \pm 0.2 \mathrm{a}$ & $1.4 \pm 0.6 \mathrm{a}$ & $20.0 \pm 0.1 \mathrm{a}$ & 3.68 & $0.55 \pm 0.02 \mathrm{a}$ & $20.1 \pm 0.7 \mathrm{~b}$ & $124.8 \pm 0.0 \mathrm{~b}$ \\
Light & $11.7 \pm 0.1 \mathrm{a}$ & $5.5 \pm 0.2 \mathrm{a}$ & $1.4 \pm 0.2 \mathrm{a}$ & $20.1 \pm 0.1 \mathrm{a}$ & 3.68 & $0.53 \pm 0.05 \mathrm{a}$ & $7.5 \pm 0 \mathrm{c}$ & $92.9 \pm 4.2 \mathrm{~d}$ \\
Classic & $11.8 \pm 0.2 \mathrm{a}$ & $5.4 \pm 0.1 \mathrm{a}$ & $1.4 \pm 0.1 \mathrm{a}$ & $20.1 \pm 0.2 \mathrm{a}$ & 3.69 & $0.56 \pm 0.01 \mathrm{a}$ & $10.7 \pm 0 \mathrm{~d}$ & $106.4 \pm 0.0 \mathrm{~d}$ \\
Premium & $11.8 \pm 0.1 \mathrm{a}$ & $5.4 \pm 0.2 \mathrm{a}$ & $1.4 \pm 0.1 \mathrm{a}$ & $20.1 \pm 0.1 \mathrm{a}$ & 3.70 & $0.54 \pm 0.02 \mathrm{a}$ & $13.2 \pm 2.3 \mathrm{~d}$ & $96.2 \pm 5.2 \mathrm{~d}$ \\
\hline
\end{tabular}

\#: as tartaric acid; * : as acetic acid; In lines, different letters denote significant differences $(\mathrm{p}<0.05)$ 


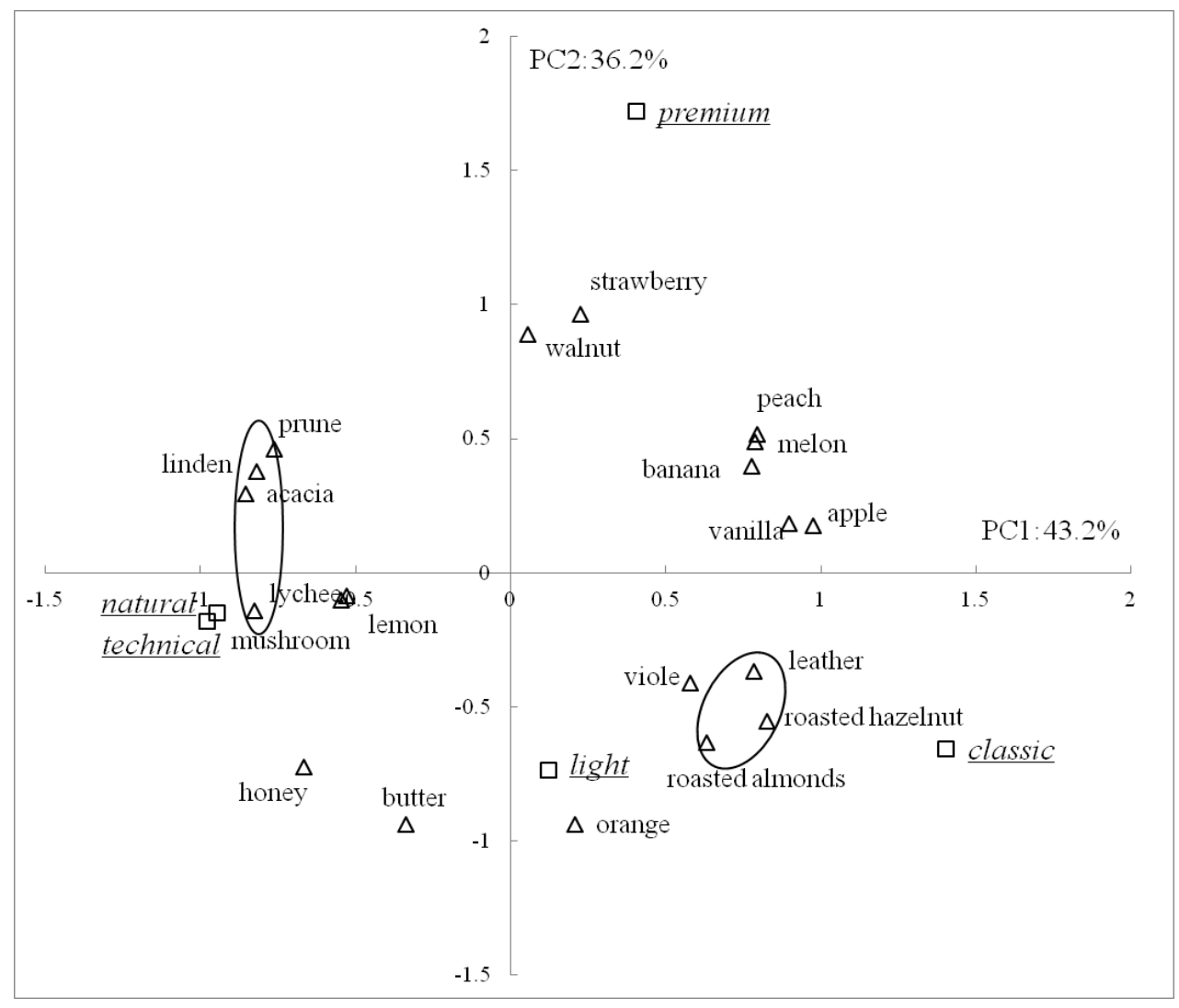

FIGURE 2

PCA analysis: aroma profile of dry white wines with different closure

with a higher level of oxidation, and it could hydrolyse rapidly to become decanoic acid and ethanol during oxidative storage; consequently it often is undetectable after long periods (Hernández-Orte et al., 2009; Lee et al., 2011).

Regarding fatty acids, four volatile compounds (isobutyric acid, isovaleric acid, octanoic acid and n-decanoic acid) were detected. No significant differences were found in them among the five closures. The subtotal concentration of the C6 to C10 fatty acids in this study (octanoic acid and n-decanoic acid) was lower than $11 \mathrm{mg} / \mathrm{L}$, which could contribute to the global aroma quality (Shinohara \& Usikubo, 1984).

\section{Descriptive sensory analysis}

Aroma characteristics were quantified by modified frequency $(M F \%)$ as shown in Table 4 . The result reveal that most of the aroma characteristics showed no significant differences, except for the terms apple, acacia, linden and caramel. The cork and synthetic closures with lower OTRs were characterised by fruity and flowery descriptors at high values, except in the case of Nomacorc light.

To better understand the differences among the different closures, a PCA of aroma characteristics was conducted. Most aroma characteristics with high variance under different closures were subjected to PCA. The first two principle components (PC1 and PC2) accounted for $43.2 \%$ and $36.2 \%$ of the total variation respectively. Figure 2 explains the loadings of the aroma characteristics in the first two PCs. Prune, linden, acacia and mushroom are located in the left quadrant of $\mathrm{PC} 1$, and strawberry, walnut, orange and butter are located in PC2. Leather, roasted hazelnut and roasted almond were located in the lower right quadrant of PC1.

Skouroumounis et al. (2005) assessed the effect of three types of closures and storage conditions on the flavour properties of a wooded Chardonnay wine. They reported that wines sealed with the synthetic closure were relatively oxidised in aroma, while wines sealed under natural bark corks showed negligible reduced characters. From both a chemical and sensory analysis, Mas et al. (2002) concluded that natural corks were the most suitable closures for wine development, with less oxidation odour. Similarly, as the most extensive report to date, Godden et al. (2001) demonstrated that natural cork and 'one plus one' stoppers scored in pineapple, citrus and reduced attributes, while synthetic stoppers had higher scores for glue-like and oxidised attributes.

In this study, as can be seen from an inspection of Fig. 2, it was apparent that the cork closures (natural and technical) were both in the negative quadrant of $\mathrm{PC} 2$, which reveals that closures with lower OTRs resulted in wines with more acacia, linden and mushroom attributes. Regarding the mushroom characteristic, it is one of the unpleasant odours of tainted wine and sometimes is described as being similar to a wet cardboard, earthy smell (Ribéreau-Gayon et al., 2000; Pons et al., 2011; Lichvanová et al., 2014). The Nomacorc premium closure was scored as most intense in fruit attributes (strawberry, walnut, peach and melon) and, although this is not clear from the plot, the premium was also rated as being high in the prune attribute. The other synthetic 
TABLE 3

Main volatile composition of white wine with different closures $(\mu \mathrm{g} / \mathrm{L})$

\begin{tabular}{|c|c|c|c|c|c|c|c|}
\hline & Compound & Aroma description & Natural & Technical & Premium & Classic & Light \\
\hline \multicolumn{8}{|c|}{ Aldehydes and phenol } \\
\hline 1 & hexanal & friut, green apple & 13791.28 & 23424.39 & 21001.21 & 22861.69 & 17713.01 \\
\hline 2 & furfural & sweet, bread-like & 552.92 & 664.47 & 703.49 & 706.03 & 623.44 \\
\hline 3 & benzaldehyde & almond & 1145.6 & 1429.32 & 1417.02 & 1673.16 & 1379.24 \\
\hline 4 & acetoin* & flowery, wet & $3618.67 \mathrm{ab}$ & $4983.47 b c$ & $5008.13 b c$ & $6021.05 \mathrm{c}$ & $3071.80 \mathrm{a}$ \\
\hline 5 & 4-ethylguaiacol & pleasant, phenolic & 243.22 & 316.05 & 269.8 & 486.63 & 530.08 \\
\hline \multicolumn{8}{|c|}{ Alcohols } \\
\hline 6 & 1-butanol** & medicinal, alcohol & $2239.08 \mathrm{a}$ & $3229.38 \mathrm{ab}$ & $5597.59 \mathrm{c}$ & $3515 b$ & $2314.41 \mathrm{a}$ \\
\hline 7 & isobutyl alcohol & fusel, alcohol & 2064.51 & 3581.97 & 3078.39 & 3827.62 & 2546.65 \\
\hline 8 & 1-hexanol & green, grass & 409.07 & 675 & 628.33 & 634.96 & 540.66 \\
\hline 9 & 2-phenylethanol* & flowery, pollen & $2008.81 \mathrm{a}$ & $2217.82 \mathrm{a}$ & $3578.40 \mathrm{ab}$ & $5120.08 b$ & $3343.82 \mathrm{a}$ \\
\hline 10 & 1 -pentanol** & alcohol & $252.59 \mathrm{~d}$ & $171.76 b$ & $223.01 \mathrm{~cd}$ & $210.79 \mathrm{c}$ & $116.1 \mathrm{a}$ \\
\hline 11 & (E)-3-hexen-1-ol & green grass, herb & 51.89 & 68.64 & 64.42 & 65.97 & 56.89 \\
\hline 12 & (Z)-3-hexen-1-ol* & green grass, herb & $70.41 b$ & $29.29 \mathrm{a}$ & $62.33 \mathrm{ab}$ & $99.72 b$ & $85.86 b$ \\
\hline 13 & 1-heptanol & grape, sweet & 84.09 & 111.12 & 127.74 & 118.61 & 105 \\
\hline 14 & 2-nonanol** & - & $522.23 \mathrm{a}$ & $2780.82 c$ & $2956.88 c$ & $2537.98 \mathrm{c}$ & $693.80 \mathrm{ab}$ \\
\hline 15 & benzyl alcohol & almond & 47.67 & 57.69 & 59.1 & 78.4 & 64.66 \\
\hline 16 & 1-octanol & intense citrus, roses & 10.11 & 12.19 & 9.03 & 16.86 & 12.16 \\
\hline \multicolumn{8}{|c|}{ Esters } \\
\hline 17 & ethyl acetate & fruit, solvent & 17108.11 & 27866.57 & 20653.93 & 25131.31 & 21188.48 \\
\hline 18 & isobutyl acetate & sweet fruit & 34.67 & 50.1 & 42.1 & 57.2 & 30.51 \\
\hline 19 & isoamyl acetate & banana & 1443.71 & 1034.39 & 1341.34 & 1264.84 & 1375.9 \\
\hline 20 & hexyl acetate & pleasant fruity, pear & 66.9 & 10.31 & 18.18 & 17.39 & 10.92 \\
\hline 21 & phenethyl acetate & pleasant, flowery & 10.58 & 11.62 & 11.92 & 13.14 & 11.88 \\
\hline 22 & ethyl lactate & lactic & 7575.82 & 12229.01 & 13542.28 & 13869.59 & 11283.72 \\
\hline 23 & ethyl hexanoate & green apple & 2078.61 & 1779.86 & 2028.59 & 1926.9 & 1963.6 \\
\hline 24 & ethyl octanoate & sweet, soap & 4512.04 & 3922.49 & 4267.37 & 3617.63 & 3737.63 \\
\hline 25 & ethyl decanoate** & fruity, fatty, pleasant & $1091.22 \mathrm{c}$ & $992.16 \mathrm{abc}$ & $943.90 \mathrm{ab}$ & $881.99 a$ & $1008 b c$ \\
\hline 26 & diethyl succinate & light fruity, wine & 800.11 & 996.22 & 1270.83 & 1214.5 & 1199.37 \\
\hline 27 & methyl octanoate & apple skin, fruity & 1.74 & 4.25 & 2.34 & 2.66 & 1.54 \\
\hline \multicolumn{8}{|c|}{ Acids } \\
\hline 28 & isobutyric acid & cheese & 3333.79 & 5131.69 & 5779.6 & 7429.69 & 4386.64 \\
\hline 29 & isovaleric acid & blue cheese & 114.04 & 157.51 & 172.4 & 161.64 & 134.17 \\
\hline 30 & octanoic acid & rancid, harsh & 4612.76 & 5373.03 & 5877.61 & 5695.66 & 5426.34 \\
\hline 31 & n-decanoic acid & fatty & 2315.56 & 2328.23 & 2199.37 & 2717.07 & 2286.71 \\
\hline
\end{tabular}

Values with different letters are significantly different by Duncan's multiple-range test at ${ }^{* *} \mathrm{p}<0.01$ and ${ }^{*} \mathrm{p}<0.05$.

closures (light and classic) were both in the positive quadrant of PC1 and the negative quadrant of PC2. They were rated high in the attributes of leather, roasted hazelnut and roasted almond, in accordance with their higher OTRs, because grilled/toasty aromas are usually products of an oxidation reaction (Skouroumounis et al., 2005). Moreover, Fig. 2 shows that the reference closure Nomacorc light, with high values of orange attribute, was rated as less oxidised than the $\mathrm{SO}_{2}$ values might indicate, which agrees with the results of Godden et al. (2001).

\section{CONCLUSION}

In this study, the effect of wine closures on the aromatic and sensory profiles of Chardonnay wine after four years' storage was accessed. Five types of closures were evaluated, namely natural cork closure, technical cork closure, Nomacorc classic, Nomacorc light and Nomacorc premium. Their effect on wine physicochemical indexes showed no significant differences, except in free and total $\mathrm{SO}_{2}$, which were higher in the wines sealed with conventional cork closures than synthetic ones. Among 31 aroma compounds, seven volatiles (acetoin, 1-butanol, 2-phenylethanol, 1-pentanol, (Z)-3-hexen-1-ol, 2-nonanol and ethyl decanoate) were 
TABLE 4

$M F \%$ of Aroma Characteristics for Sample Wines.

\begin{tabular}{|c|c|c|c|c|c|c|}
\hline \multirow[b]{2}{*}{ Characteristics } & \multicolumn{2}{|c|}{ cork } & \multicolumn{3}{|c|}{ synthetic } & \multirow[b]{2}{*}{ Sig. } \\
\hline & natural & technical & light & classic & premium & \\
\hline apple & - & - & 9.5 & 16.5 & 13.5 & $*$ \\
\hline vanilla & - & - & - & 16.5 & 9.5 & ns \\
\hline acacia & 25.2 & 25.2 & - & - & 13.5 & $*$ \\
\hline linden & 16.5 & 9.5 & - & - & - & $*$ \\
\hline roasted hazelnut & - & - & 16.5 & 38.1 & - & ns \\
\hline pineapple & 87.4 & 35.7 & 34.4 & 50.5 & 35.7 & ns \\
\hline mushroom & 23.4 & 19.1 & - & - & - & ns \\
\hline melon & 16.5 & - & 13.5 & 40.5 & 45.7 & ns \\
\hline peach & 13.5 & 13.5 & 9.5 & 43.7 & 42.6 & ns \\
\hline leather & - & - & - & 13.5 & - & ns \\
\hline osmanthus & 21.3 & 9.5 & - & 16.5 & - & ns \\
\hline banana & 21.3 & 27.0 & 16.5 & 59.5 & 52.2 & ns \\
\hline prune & 16.5 & 19.1 & 16.5 & - & 19.1 & ns \\
\hline violet & 9.5 & - & - & 23.4 & - & ns \\
\hline lychee & - & 9.5 & - & - & - & ns \\
\hline lemon & 23.4 & - & - & - & - & ns \\
\hline strawberry & - & - & - & - & 13.5 & ns \\
\hline butter & 19.1 & 19.1 & 19.1 & 16.5 & - & ns \\
\hline caramel & - & 9.5 & 81.5 & 57.2 & 61.8 & $* *$ \\
\hline orange & 48.6 & 61.8 & 79.8 & 73.9 & 27.0 & ns \\
\hline walnut & 21.3 & - & 16.5 & - & 57.2 & ns \\
\hline honey & 25.2 & 27.0 & 19.1 & 13.5 & - & ns \\
\hline roasted almonds & - & - & 16.5 & 13.5 & - & ns \\
\hline
\end{tabular}

significantly affected by the wine closures in this study. By sensory evaluation, the cork closures (natural and technical) and Nomacorc synthetic closures (classic and premium) with lower OTRs were found to preserve more fruity and flowery attributes. However, the cork closures also provided the offflavour 'mushroom' odour to the wines after four years' bottle storage. The Nomacorc classic and light closures contributed more grilled characteristics to the wines.

\section{LITERATURE CITED}

Azzara, C.D. \& Campbell, L.B., 1992. Off-flavors of dairy products. In: George, C. (ed). Developments in food science, vol. 28. Elsevier, Amsterdam. pp. 329-374.

Brajkovich, M., Tibbits, N., Peron, G., Lund, C.M., Dykes, S.I., Kilmartin, P.A. \& Nicolau, L., 2005. Effect of screw cap and cork closures on SO levels and aromas in a Sauvignon blanc wine. J. Agr. Food Chem. 53, 10006-10011.

Caille, S., Samson, A., Wirth, J., Dieval, J.B., Vidal, S. \& Cheynier, V., 2010. Sensory characteristics changes of red Grenache wines submitted to different oxygen exposures pre and post bottling. Anal. Chim. Acta 660, $35-42$.

Câmara, J., Alves, M. \& Marques, J., 2006. Changes in volatile composition of Madeira wines during their oxidative ageing. Anal. Chim. Acta 563, 188197.
Cathy, F., 2007. Closure Survey Report. Available at: doi:http://www winebusiness.com/wbm/?go=getArticle \&dataId $=48558$.

Cathy, F., 2008. Closure Survey Report. Available at doi:http://www. winebusiness.com/wbm/?go $=$ getArticle \&dataId $=56819$.

Chatonnet, P., Labadie, D. \& Gubbiotti, M., 2000. Comparative study of different types of corkage. Revue des Oenologues et des Techniques Vitivinicoles et Oenologiques 95, 7-13.

Dravnieks, A. (Ed.), 1985. Atlas of odor character profiles. Philadelphia, PA: ASTM.

Escudero, A., Asensio, E., Cacho, J. \& Ferreira, V., 2002. Sensory and chemical changes of young white wines stored under oxygen. An assessment of the role played by aldehydes and some other important odorants. Food Chem. 77, 325-331.

Field, J., Robinson, E., Lattey, K., Høj, P.B., Coulter, A.D., Valente, P., Gishen, M., Godden, P. \& Francis, L., 2003. The AWRI closure trial: Sensory evaluation data 36 months after bottling. Aust. N.Z. Grapegrow. Winemak., 475, 59-64.

GB/T 15038-2006, 2006. Analytical methods of wine and fruit wine. Beijing: China Standard Press.

Godden, P., Francis, L., Field, J., Gishen, M., Coulter, A., Valente, P., Høj, P. \& Robinson, E., 2001. Wine bottle closures: Physical characteristics and effect on composition and sensory properties of a Semillon wine 1 . Performance up to 20 months post bottling. Aust. J. Grape Wine Res. 7, 64-105. 
He, J., Zhou, Q., Peck, J., Soles, R. \& Qian, M.C., 2013. The effect of wine closures on volatile sulfur and other compounds during post-bottle ageing. Flavour Frag. J. 28, 118-128.

Hernández-Orte, P., Lapeña, A., Escudero, A., Astrain, J., Baron, C., Pardo, I., Polo, L., Ferrer, S., Cacho, J. \& Ferreira, V., 2009. Effect of microoxygenation on the evolution of aromatic compounds in wines: Malolactic fermentation and ageing in wood. LWT-Food Sci. Technol. 42, 391-401.

Karbowiak, T., Mansfield, A.K., Barrera-García, V.D. \& Chassagne, D., 2010. Sorption and diffusion properties of volatile phenols into cork. Food Chem. 122, 1089-1094.

Lee, D.H., Kang, B.S. \& Park, H.J., 2011. Effect of oxygen on volatile and sensory characteristics of Cabernet Sauvignon during secondary shelf life. J. Agr. Food Chem. 59, 11657-11666.

Lichvanová, Z., Ilbeigi, V., Sabo, M., Tabrizchi, M. \& Matejčík, Š., 2014. Using corona discharge-ion mobility spectrometry for detection of 2, 4, 6-trichloroanisole. Talanta 127, 239-243.

Lopes, P., Saucier, C. \& Glories, Y., 2005. Nondestructive colorimetric method to determine the oxygen diffusion rate through closures used in winemaking. J. Agr. Food Chem. 53, 6967-6973.

Lopes, P., Saucier, C., Teissedre, P.L. \& Glories, Y., 2006. Impact of storage position on oxygen ingress through different closures into wine bottles. J. Agr. Food Chem. 54, 6741-6746.

Lopes, P., Silva, M.A., Pons, A., Tominaga, T., Lavigne, V., Saucier, C., Darriet, P., Teissedre, P.L. \& Dubourdieu, D., 2009. Impact of oxygen dissolved at bottling and transmitted through closures on the composition and sensory properties of a Sauvignon Blanc wine during bottle storage. J. Agric. Food Chem. 57, 10261-10270.

Mas, A., Puig, J., Lladoa, N. \& Zamora, F., 2002. Sealing and storage position effects on wine evolution. J. Food Sci. 67, 1374-1378.

OIV, 2009. International methods of analysis of wines and musts. Paris: International Organisation of Vine and Wine.

Park, Y.C., Shaffer, C.E.H. \& Bennett, G.N., 2009. Microbial formation of esters. Appl. Microbiol. Biotechnol. 85, 13-25.

Pons, M., Dauphin, B., La Guerche, S., Pons, A., Lavigne-Cruege, V., Shinkaruk, S., Bunner, D., Richard, T., Monti, J.P. \& Darriet, P., 2011. Identification of impact odorants contributing to fresh mushroom off-flavor in wines: Incidence of their reactivity with nitrogen compounds on the decrease of the olfactory defect. J. Agr. Food Chem. 59, 3264-3272.
Ribéreau-Gayon, P., Glories, Y., Maujean, A. \& Dubourdieu, D., 2000. Handbook of enology. The chemistry of wine and stabilisation and treatments, vol. 2. Wiley, Chichester.

Shinohara, T. \& Usikubo, M., 1984. Apparatus for preserving liquid in automatic analyzer. US Patent 4455280A. Available at: https://www.google. com.ar/patents/US4455280

Silva, M.A., Julien, M., Jourdes, M. \& Teissedre, P.L., 2011. Impact of closures on wine post-bottling development: A review. Eur. Food Res. Technol. 233, 905-914.

Silva, S.P., Sabino, M.A., Fernandes, E.M., Correlo, V.M., Boesel, L.F. \& Reis, R.L., 2005. Cork: Properties, capabilities and applications. Int. Mater. Rev. 50, 345-365.

Silvestre, A.J.D., Pascoal, N.C. \& Gandini, A., 2008. Cork and suberins: Major sources, properties and applications. In: Belgacem, M.N. \& Gandini, A. (eds). Monomers, polymers and composites from renewable resources. Elsevier, Amsterdam. pp. 305 - 320.

Skouroumounis, G.K., Kwiatkowski, M., Francis, I.L., Oakey, H., Capone, D.L., Duncan, B., Sefton, M.A. \& Waters, E.J., 2005. The impact of closure type and storage conditions on the composition, colour and flavour properties of a Riesling and a wooded Chardonnay wine during five years' storage. Aust. J. Grape Wine Res. 11, 369-377.

Tao, Y. \& Zhang, L., 2010. Intensity prediction of typical aroma characters of Cabernet Sauvignon wine in Changli County (China). LWT-Food Sci. Technol. 43, 1550-1556.

Tominaga, T., Murat, M.L. \& Dubourdieu, D., 1998. Development of a method for analyzing the volatile thiols involved in the characteristic aroma of wines made from Vitis vinifera L. cv. Sauvignon blanc. J. Agr. Food Chem. 46, 1044-1048.

Ugliano, M., 2013. Oxygen contribution to wine aroma evolution during bottle aging. J. Agric. Food Chem. 61, 6125-6136.

Wirth, J., Caillé, S., Souquet, J.M., Samson, A., Dieval, J.B., Vidal, S., Fulcrand, H. \& Cheynier, V., 2012. Impact of post-bottling oxygen exposure on the sensory characteristics and phenolic composition of Grenache rosé wines. Food Chem. 132, 1861-1871.

Zhang, M., Xu, Q., Duan, C., Qu, W. \& Wu, Y., 2007. Comparative study of aromatic compounds in young red wines from Cabernet Sauvignon, Cabernet Franc, and Cabernet Gernischet varieties in China. J. Food Sci. 72, C248-C252. 